\title{
Circulating gamma-glutamyl transferase and development of specific breast cancer subtypes: findings from the Apolipoprotein Mortality Risk (AMORIS) cohort
}

Lydia Shackshaft ${ }^{1}$, Mieke Van Hemelrijck ${ }^{1,4}$, Hans Garmo ${ }^{1,2}$, Håkan Malmström³ ${ }^{3}$ Mats Lambe ${ }^{2,4}$, Niklas Hammar ${ }^{5,6}$, Göran Walldius ${ }^{6}$, Ingmar Jungner ${ }^{7}$ and Wahyu Wulaningsih ${ }^{1,8^{*}}$

\begin{abstract}
Background: Different etiological pathways may precede development of specific breast cancer subtypes and impact prevention or treatment strategies. We investigated the association between gamma-glutamyl transferase (GGT) and development of specific breast cancer subtypes based on oestrogen receptor (ER), progesterone receptor (PR) and HER2 status.

Methods: We included 231,283 cancer-free women in a Swedish cohort. Associations between GGT and breast cancer subtypes were investigated with nested case-control and case-case analyses. We used logistic regression models to assess serum GGT in relation to breast cancer subtype, based on individual and combined receptor status.

Results: Positive associations were found between serum GGT and development of ER+, ER- and PR+ breast cancers compared to controls (odds ratio (OR) 1.14 (95\% confidence interval (CI) 1.08-1.19), $1.11(1.01-1.23$ ) and 1. 18 (1.12-1.24), respectively) and of ER+/PR+ tumours. We found inverse associations between GGT levels and PR- breast cancers compared to PR+ (OR 0.87 (0.80-0.95)), between ER+/PR- tumours compared to ER+/PR+ tumours and between ER-/PR-/HER+ compared to ER+/HER2 or PR+/HER2 tumours (OR 0.55 (95\% Cl 0.34-0.90).

Conclusion: The observed associations between pre-diagnostic serum GGT and different breast cancer subtypes may indicate distinct underlying pathways and require further investigations to tease out their clinical implications.
\end{abstract}

Keywords: GGT, Breast cancer, Glucose, Triglycerides, Prospective study

\section{Background}

Increased levels of serum gamma-glutamyl transferase (GGT) is a marker of oxidative stress [1], which may lead to tumour development, progression and metastasis [2] through modification of signalling pathways and DNA damage [2-4]. We previously showed an association between elevated serum GGT and risk of breast cancer in Swedish women [5], which were supported in a large systematic review and meta-analysis [6]. However, the association between circulating GGT and breast

\footnotetext{
* Correspondence: wahyu.wulaningsih@kcl.ac.uk

'Division of Cancer Studies, Cancer Epidemiology Group, King's College London, Faculty of Life Sciences \& Medicine, Guy's Hospital, 3rd Floor, Bermondsey Wing, London SE1 9RT, UK

${ }^{8}$ MRC Unit for Lifelong Health and Ageing at University College London, London, UK

Full list of author information is available at the end of the article
}

cancer subtype is unclear. Development of specific breast cancer subtypes significantly impacts therapeutic decisions and prognosis, but their underlying mechanisms remain elusive. To assess the role of oxidative stress, we now investigated the association between pre-diagnostic GGT and breast cancer subtype in nested case-control and case-case studies in a large Swedish cohort.

\section{Methods}

Study population

The AMORIS study has been described in detail elsewhere [5, 7-9]. This cohort includes 812,073 individuals who underwent laboratory examination at the Central Automation Laboratory in Stockholm between 1985 and 1996 [9]. The study complied with the declaration of 
Helsinki and was approved by the Ethics Review Board of the Karolinska institute.

From the AMORIS cohort we identified 231,283 cancer-free women aged 20 years or older with baseline measurements of serum GGT. These women were followed until they developed breast cancer, died, emigrated, or until the end of the study (31 December 2011), whichever came first. A total of 10,861 breast cancers (4.7\%) were diagnosed during follow-up. Among them, $6934(63.8 \%)$ had available information on oestrogen receptor (ER) status, 7145 (65.8\%) had information on progesterone receptor (PR) status, and 2197 (20.2\%) had additional information on HER2 status. A nested casecontrol study was performed where for each case with information on receptor status, we used incidence density sampling to select ten controls among all women in the cohort who were alive and did not have breast cancer at the time of diagnosis of the case. Cases and controls were matched for age group (less or more than 50 years old) as an indicator for menopausal status [10] because menopausal status was only available for cases. The same sets of cases were included in the case-case analysis.

\section{Breast cancer diagnosis and subtype}

We classified breast cancer subtype based on ER and $P R$ and their combinations. In the subgroup with information on HER2, we defined four tumour subtypes (ER+/HER2- or PR+/HER2-, ER+/HER2+ or PR+/HER2+, ER-/PR-/HER2+, and ER-/PR-/HER2- (triple negative)) as previously described (Additional file 1: Figure S1) [11]. These subtypes share similar profiles with molecular phenotypes luminal A, luminal B, HER2 type and triple negative $[12,13]$.

\section{Assessment of exposures and covariates}

All laboratory analyses were performed by automated techniques at the CALAB laboratory, Stockholm, Sweden. GGT (U/L) was determined using the reference method recommended by the International Federation of Clinical Chemistry and Laboratory Medicine (IFCC) [5, 14]. The coefficient of variation was $\leq 6.0 \%$. Samples were prospectively measured prior to assignment to cases or controls. Levels of GGT were skewed and logarithmically transformed. We additionally categorised GGT into quartiles.

From the registry linkage in AMORIS [5, 9], we collected information on socioeconomic status, education level, parity, menopausal status at diagnosis, and comorbidities using Charlson co-morbidity index (CCI) $[15,16]$. Serum triglycerides and glucose were measured enzymatically [17].

\section{Statistical analysis}

In the nested case-control analysis, we used conditional logistic regression models to assess any association between log-transformed and quartiles of GGT and overall and specific breast cancer subtypes. A test for trend was performed by using GGT quartiles as an ordinal scale. We estimated odds ratios (ORs) of ER and PR status individually compared to matched controls based on these measures of serum GGT. Subsequently we compared GGT levels of cases with controls based on combined ER and PR subtypes.

We further conducted a case-case analysis to compare different breast cancer subtypes [18]. Binary and multinomial logistic regression models were used to assess logtransformed levels and quartiles of GGT in relation to breast cancer subtype, both by individual ER or PR status, combined ER/PR status and ER/PR/HER2 status. Since ER and PR status was available since follow-up started and the information of HER2 status was only available after 2006, we performed a sensitivity analysis only including cases with complete information on the three receptors.

All models were adjusted for age, socioeconomic status, education and parity, and time interval between GGT measurement and diagnosis. We additionally controlled for menopausal status in the case-case analysis. Adjustment for CCI was performed to take into account existing co-morbidities $[1,5,19,20]$. We further adjusted for serum glucose and triglycerides to reduce potential confounding from metabolic disorders [11, 21-23]. All analyses were conducted with Statistical Analysis Systems (SAS) release 9.4 (SAS Institute, Cary, NC, USA).

\section{Results}

\section{Case-control analysis}

The mean age of diagnosis was 61.68 years and most women were postmenopausal (Additional file 1: Table S1). Serum GGT was slightly higher in cases than in controls. Overall, higher log-transformed GGT correlated with higher odds of any breast cancer (OR 1.13, 95\% confidence interval (CI) 1.08-1.19). There was a positive association between continuous levels of GGT and development of ER+, ER-, and $\mathrm{PR}+$ breast cancers (Table 1), with the strongest association seen for $\mathrm{PR}+\mathrm{tu}-$ mours (OR 1.18, 95\% CI 1.12-1.24). Results were similar with GGT quartiles.

We subsequently investigated the association between serum GGT and combined receptor subtypes of breast cancer based on ER/PR status. A significant positive association between log-transformed GGT and development of ER+/PR+ tumours was noted (OR 1.18; 95\% CI 1.12-1.24). Adjustment for serum levels of glucose and triglycerides did not alter these findings (results not shown). Association between GGT and ER- cancer was no longer seen, whilst others remained, in a sensitivity analysis only including cases with complete receptor information (results not shown). 
Table 1 Conditional logistic regression model with breast cancer subtype as main outcome

\begin{tabular}{|c|c|c|c|c|c|c|}
\hline$\overline{G G T ~ U / L ~}$ & $\begin{array}{l}\text { Number of hormone } \\
\text { receptor-positive cases }\end{array}$ & Number of controls & OR $(95 \% \mathrm{Cl})$ & $\begin{array}{l}\text { Number of hormone } \\
\text { receptor-negative cases }\end{array}$ & Number of controls & OR $(95 \% \mathrm{Cl})$ \\
\hline \multicolumn{7}{|c|}{ ER status versus control } \\
\hline GGT log & 5939 & 59390 & $1.14(1.08-1.19)$ & 1295 & 12950 & $1.11(1.01-1.23)$ \\
\hline $0-11.40$ & 1310 & 13100 & 1 (Ref) & 296 & 2960 & 1 (Ref) \\
\hline $11.40-15.00$ & 1424 & 14240 & $1.08(1.00-1.17)$ & 308 & 3080 & $1.04(0.88-1.23)$ \\
\hline $15.00-21.60$ & 1585 & 15850 & $1.11(1.03-1.20)$ & 340 & 3400 & 1.08(0.92-1.28) \\
\hline$\geq 21.60$ & 1620 & 16200 & $1.25(1.15-1.35)$ & 351 & 3510 & $1.21(1.02-1.43)$ \\
\hline$P_{\text {trend }}$ & & & $<0.0001$ & & & 0.03 \\
\hline \multicolumn{7}{|c|}{ PR status versus control } \\
\hline GGT log & 4938 & 49380 & $1.18(1.12-1.24)$ & 2207 & 22070 & $1.06(0.98-1.15)$ \\
\hline $0-11.40$ & 1068 & 10680 & 1 (Ref) & 512 & 5120 & 1 (Ref) \\
\hline $11.40-15.00$ & 1175 & 11750 & $1.09(1.00-1.19)$ & 531 & 5310 & $1.04(0.91-1.18)$ \\
\hline $15.00-21.60$ & 1324 & 13240 & $1.16(1.06-1.26)$ & 580 & 5800 & 1.02(0.90-1.16) \\
\hline$\geq 21.60$ & 1371 & 13710 & $1.33(1.22-1.45)$ & 584 & 5840 & $1.11(0.97-1.26)$ \\
\hline$P_{\text {trend }}$ & & & $<0.0001$ & & & 0.18 \\
\hline
\end{tabular}

Hormone receptor-positive or -negative cases referred to cancer subtypes based on individual ER or PR status. Controls without breast cancer were the referent groups. All models were adjusted for age at diagnosis, socioeconomic status, education, parity, $\mathrm{CCl}$, and interval between measurement and cancer diagnosis or control selection date

\section{Case-case analysis}

Cases were less likely to be PR- compared to PR+ with increasing log-transformed GGT (OR 0.87, 95\% CI 0.80-0.95). A similar trend was seen for quartiles of GGT. No association was found for ER- cancers, with $\mathrm{ER}+$ cancers as the referent.
We subsequently investigated any association between serum GGT and breast cancer subtypes based on the combination of ER/PR and ER/PR/HER2 status (Fig. 1). Compared to $\mathrm{ER}+/ \mathrm{PR}+$ tumours, increasing GGT was associated with a lower odds of $\mathrm{ER}+/ \mathrm{PR}$ - tumours (OR $0.83,95 \%$ CI $0.73-0.93$ for each log unit increase in

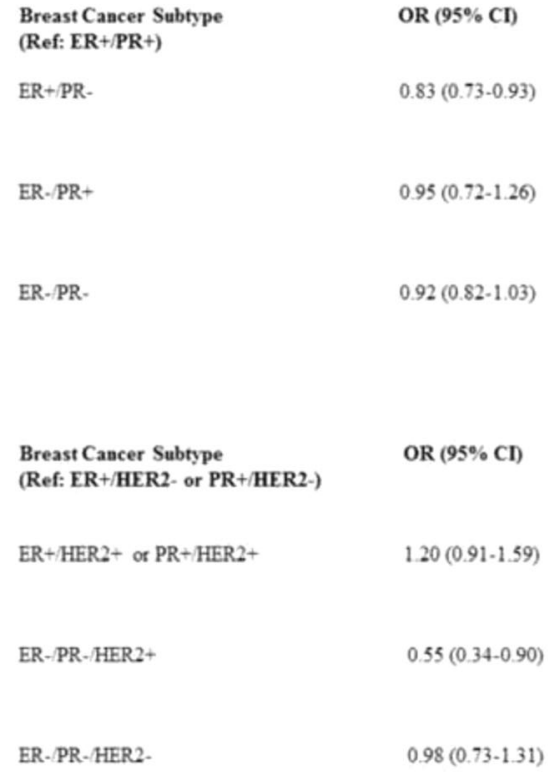

OR $(95 \% \mathrm{CI})$


Fig. 1 Multinomial logistic regression analysis for log-transformed levels of GGT with breast cancer subtype as outcome variable. ER+/PR+ and ER+/HER2- or PR+/HER2- assigned as reference values. All models were adjusted for age at diagnosis, menopausal status, socioeconomic status, education, parity, $\mathrm{CCl}$, and interval between measurement and cancer diagnosis 
GGT). A similar but weaker trend was seen for ER-/PRtumours (Additional file 1: Table S2). Associations were slightly weaker when limited to cases with complete information on the three receptors, e.g. OR for ER+/PRtumours: 0.83 (95\% CI 0.67-1.02) for each log-unit increase in GGT.

We also found an inverse trend between GGT and odds of being diagnosed with ER-/PR-/HER2+ cancers (OR 0.55, 95\% CI 0.34-0.90 when compared to the referent group ER+/HER2- or PR+/HER2- breast cancers). No marked difference across GGT levels was observed for other subtypes. Additional adjustments for serum levels of glucose and triglycerides did not alter these observations (results not shown).

\section{Discussion}

Increasing serum levels of GGT corresponded to increased odds of ER+, ER- and PR+ tumours but not related to higher risk of PR- breast cancers. Our findings when comparing different subtypes also suggested associations between GGT levels and specific breast cancer subtypes.

Oxidative stress may contribute to development of ER+ breast cancers by modifying the structure and function of redox-sensitive ERs on the cell surface, which reduces expression of an oxidant-sensitive set of oestrogen-inducible genes, including genes involved in cell growth, invasion, and PR expression [24]. This may correlate with suppression of the PR gene $[24,25]$. We found that higher levels of GGT were associated with relatively attenuated odds of ER- subtype. These conflicting results might imply more complex underlying mechanisms. The negative association found between GGT and ER-/PR-/HER2+ breast cancers may support previous notions that HER2-overexpressing tumours have lower glutathione levels and GGT activity [26, 27]. However, this would require further confirmation in larger studies. It is also possible that this finding on HER2 was driven by the inverse association between GGT and PR-compared to PR+ breast cancers.

Our results may support distinct aetiological pathways preceding breast cancer subtypes, in particular PR- cancers. Previously, different associations with breast cancer subtypes have been reported with parity, first-time births, breastfeeding and oral contraceptive [11, 28, 29]. Obesity [11, 21-23] and dietary fat intake [30-32] may also affect subtype development via hormonal modulation, increased oxidative stress and inflammation [22]. Similar roles have been indicated for circulating glucose $[17,33,34]$. Therefore, increased GGT associated with increased risk of breast cancer may partly be acting as a marker of these metabolic disorders. Nonetheless, our results were unaltered when adjusted for serum glucose and triglycerides.
The strength of this study is the large number of women included with complete follow-up information. The AMORIS population is similar to the general working population of Stockholm in terms of socioeconomic status and ethnicity [5]. There was limited information on receptor status in earlier diagnoses. However, results were similar when limited to data with complete receptor information, i.e. diagnoses from 2007 onwards. Information on other risk factors such as hormone-replacement therapy, body mass index and alcohol intake was not available, which necessitates future studies incorporating this information. With respect to alcohol, however, the blood samples were collected prior to the major increase in alcohol use in women.

\section{Conclusion}

Pre-diagnostic serum GGT levels are associated with specific female breast cancer subtypes. Given prior evidence showing increased GGT to be associated with other lifestyle-related disorders, it is important to consider GGT as a proxy of these factors. Understanding of this complex association may lead to mechanistic studies to confirm the role of oxidative stress in specific breast cancer subtypes, which may have clinical implications.

\section{Additional file}

Additional file 1: Supplementary tables. (DOCX 39 kb)

Abbreviations

CCl: Charlson co-morbidity index; ER: Oestrogen receptor; GGT: Gammaglutamyl transferase; HER2: Human epidermal growth factor 2; OR: Odds ratio; PR: Progesterone receptor

\section{Acknowledgements}

Not applicable.

\section{Funding}

The research was funded/supported by the Swedish Cancer Foundation (Cancerfonden) and the National Institute for Health Research (NIHR) Biomedical Research Centre based at Guy's and St Thomas' NHS Foundation Trust and King's College London. This study was also supported by grants from the Gunnar and Ingmar Jungner Foundation for Laboratory Medicine, Stockholm, Sweden.

Open access for this article was funded by King's College London.

\section{Availability of data and materials}

Data used in this research are stored and governed by the AMORIS Steering Committee at Karolinska Institutet.

\section{Authors' contributions}

LS, HG, MVH and WW conceptualised and designed the study. HM, ML, NH, GR and IJ provided materials used in the study. LS, HG and WW performed the statistical analysis with critical feedback from other authors. LS wrote the first draft of the manuscript. All authors reviewed, edited and finalised the manuscript. All authors read and approved the final manuscript.

Authors' information Not applicable. 


\section{Competing interests}

Niklas Hammar is employed by AstraZeneca. However, the views expressed in this study are his own and not those of AstraZeneca's.

\section{Consent for publication}

Not applicable.

\section{Ethical approval and consent to participate}

The study complied with the declaration of Helsinki and was approved by the Ethics Review Board of the Karolinska institute. Anonymity of participants was maintained throughout the study. Participant informed consent was not required for this register linkage study.

\section{Author details}

'Division of Cancer Studies, Cancer Epidemiology Group, King's College London, Faculty of Life Sciences \& Medicine, Guy's Hospital, 3rd Floor, Bermondsey Wing, London SE1 9RT, UK. ${ }^{2}$ Regional Cancer Centre, Uppsala, Sweden. ${ }^{3}$ Unit of Epidemiology, Institute of Environmental Medicine, Karolinska Institutet, Stockholm, Sweden. ${ }^{4}$ Department of Medical Epidemiology and Biostatistics, Karolinska Institutet, Stockholm, Sweden ${ }^{5}$ AstraZeneca R\&D, Mölndal, Sweden. ${ }^{6}$ Unit of Cardiovascular Epidemiology, Institute of Environmental Medicine, Karolinska Institutet, Stockholm, Sweden. ${ }^{7}$ Department of Medicine, Clinical Epidemiological Unit, Karolinska Institutet and CALAB Research, Stockholm, Sweden. ${ }^{8}$ MRC Unit for Lifelong Health and Ageing at University College London, London, UK.

\section{Published online: 06 March 2017}

\section{References}

1. Fentiman IS. Gamma-glutamyl transferase: risk and prognosis of cancer. Br J Cancer. 2012;106(9):1467.

2. Weinberg F, Chandel NS. Reactive oxygen species-dependent signaling regulates cancer. Cell Mol Life Sci. 2009;66(23):3663-73.

3. Corti A, Duarte TL, Giommarelli C, De Tata V, Paolicchi A, Jones GDD, et al. Membrane gamma-glutamyl transferase activity promotes iron-dependent oxidative DNA damage in melanoma cells. Mutat Res/Fundam Mol Mecha Mutagenesis. 2009;669(1-2):112-21.

4. Paolicchi A, Dominici S, Pieri L, Maellaro E, Pompella A. Glutathione catabolism as a signaling mechanism. Biochem Pharmacol. 2002;64(5-6):1027-35.

5. Van Hemelrijck M, Jassem W, Walldius G, Fentiman IS, Hammar N, Lambe M, et al. Gamma-glutamyltransferase and risk of cancer in a cohort of 545,460 persons-the Swedish AMORIS study. Eur J Cancer. 2011;47(13):2033-41.

6. Kunutsor SK, Apekey TA, Van Hemelrijck M, Calori G, Perseghin G. Gamma glutamyltransferase, alanine aminotransferase and risk of cancer: systematic review and meta-analysis. Int J Cancer. 2015:136(5):1162-70.

7. Holme I, Aastveit AH, Hammar N, Jungner I, Walldius G. Inflammatory markers, lipoprotein components and risk of major cardiovascular events in 65,005 men and women in the Apolipoprotein MOrtality RISk study (AMORIS). Atherosclerosis. 2010;213(1):299-305.

8. Van Hemelrijck M, Garmo H, Holmberg L, Walldius G, Jungner I, Hammar N, et al. Prostate cancer risk in the Swedish AMORIS study. Cancer. 2011; 117(10):2086-95

9. Wulaningsih W, Holmberg L, Garmo H, Malmstrom H, Lambe M, Hammar N, et al. Prediagnostic serum inflammatory markers in relation to breast cancer risk, severity at diagnosis and survival in breast cancer patients. Carcinogenesis. 2015:36(10):1121-8

10. Gaur A, Collins H, Wulaningsih W, Holmberg L, Garmo H, Hammar N, et al. Iron metabolism and risk of cancer in the Swedish AMORIS study. Cancer Causes Control. 2013;24(7):1393-402.

11. Yang XR, Chang-Claude J, Goode EL, Couch FJ, Nevanlinna H, Milne RL, et al. Associations of breast cancer risk factors with tumor subtypes: a pooled analysis from the Breast Cancer Association Consortium studies. J Natl Cancer Inst. 2011;103(3):250-63.

12. Howlader N, Altekruse SF, Li Cl, Chen WW, Clarke CA, Ries LAG, et al. US Incidence of Breast Cancer Subtypes Defined by Joint Hormone Receptor and HER2 Status. J Natl Cancer Inst. 2014;106(5):dju055. https://doi.org/10. 1093/jnci/dju055.

13. Onitilo AA, Engel JM, Greenlee RT, Mukesh BN. Breast cancer subtypes based on ER/PR and Her2 expression: comparison of clinicopathologic features and survival. Clin Med Res. 2009;7(1-2):4-13.
14. Melvin JC, Rodrigues C, Holmberg L, Garmo H, Hammar N, Jungner I, et al. Gamma-glutamyl transferase and C-reactive protein as alternative markers of metabolic abnormalities and their associated comorbidites: a prospective cohort study. Int J Mol Epidemiol Genet. 2012;3(4):276-85.

15. Lindhagen L, Van Hemelrijck M, Robinson D, Stattin P, Garmo H. How to model temporal changes in comorbidity for cancer patients using prospective cohort data. BMC Med Inform Decis Mak. 2015;15:96. 015-0217-8.

16. Wulaningsih W, Michaelsson K, Garmo H, Hammar N, Jungner I, Walldius G, et al. Serum calcium and risk of gastrointestinal cancer in the Swedish AMORIS study. BMC Public Health. 2013;13:663. 2458-13-663.

17. Wulaningsih W, Holmberg L, Garmo H, Zethelius B, Wigertz A, Carroll P, et al. Serum glucose and fructosamine in relation to risk of cancer. PLoS One. 2013:8(1):e54944.

18. Martinez ME, Cruz Gl, Brewster AM, Bondy ML, Thompson PA. What can we learn about disease etiology from case-case analyses? Lessons from breast cancer. Cancer Epidemiol Biomarkers Prev. 2010;19(11):2710-4.

19. Grundy SM. Gamma-glutamyl transferase: another biomarker for metabolic syndrome and cardiovascular risk. Arterioscler Thromb Vasc Biol. 2007;27(1):4-7.

20. Yokoyama H. Gamma glutamyl transpeptidase (gammaGTP) in the era of metabolic syndrome. Nihon Arukoru Yakubutsu Igakkai Zasshi. 2007;42(3): 110-24.

21. Munsell MF, Sprague BL, Berry DA, Chisholm G, Trentham-Dietz A. Body mass index and breast cancer risk according to postmenopausal estrogenprogestin use and hormone receptor status. Epidemiol Rev. 2014:36:114-36.

22. Renehan AG, Tyson M, Egger M, Heller RF, Zwahlen M. Body-mass index and incidence of cancer: a systematic review and meta-analysis of prospective observational studies. Lancet. 2008;371(9612):569-78.

23. van den Brandt PA, Spiegelman D, Yaun S, Adami H, Beeson L, Folsom AR, et al. Pooled analysis of prospective cohort studies on height, weight, and breast cancer risk. Am J Epidemiol. 2000;152(6):514-27.

24. Yau C, Benz CC. Genes responsive to both oxidant stress and loss of estrogen receptor function identify a poor prognosis group of estrogen receptor positive primary breast cancers. Breast Cancer Res. 2008;10(4):R61

25. Neven P, Van Gorp T, Deraedt K. A gene signature of loss of oestrogen receptor (ER) function and oxidative stress links ER-positive breast tumours with an absent progesterone receptor and a poor prognosis. Breast Cancer Res. 2008:10(5):109.

26. Perquin M, Oster T, Maul A, Froment N, Untereiner M, Bagrel D. The glutathione-related detoxification system is increased in human breast cancer in correlation with clinical and histopathological features. J Cancer Res Clin Oncol. 2001;127(6):368-74

27. Victorino VJ, Campos FC, Herrera AC, Colado Simao AN, Cecchini AL, Panis $\mathrm{C}$, et al. Overexpression of HER-2/neu protein attenuates the oxidative systemic profile in women diagnosed with breast cancer. Tumour Biol. 2014;35(4):3025-34.

28. Colditz GA, Rosner BA, Chen WY, Holmes MD, Hankinson SE. Risk factors for breast cancer according to estrogen and progesterone receptor status. $J$ Natl Cancer Inst. 2004:96(3):218-28

29. Work ME, John EM, Andrulis IL, Knight JA, Liao Y, Mulligan AM, et al. Reproductive risk factors and oestrogen/progesterone receptor-negative breast cancer in the Breast Cancer Family Registry. Br J Cancer. 2014;1 10(5): 1367-77. doi:10.1038/bjc.2013.807.

30. Melvin JC, Seth D, Holmberg L, Garmo H, Hammar N, Jungner I, et al. Lipid profiles and risk of breast and ovarian cancer in the Swedish AMORIS study. Cancer Epidemiol Biomarkers Prev. 2012;21(8):1381-4.

31. Ni H, Liu H, Gao R. Serum lipids and breast cancer risk: a meta-analysis of prospective cohort studies. PLoS One. 2015;10(11):e0142669. doi:10.1371/ journal.pone.0142669.

32. Sieri S, Chiodini P, Agnoli C, Pala V, Berrino F, Trichopoulou A, et al. Dietary fat intake and development of specific breast cancer subtypes. J Natl Cancer Inst. 2014:106(5):dju068. https://doi.org/10.1093/jnci/dju068.

33. Boyle $\mathrm{P}$, Koechlin A, Pizot C, Boniol M, Robertson C, Mullie P, et al. Blood glucose concentrations and breast cancer risk in women without diabetes: a meta-analysis. Eur J Nutr. 2013;52(5):1533-40.

34. Crawley DJ, Holmberg L, Melvin JC, Loda M, Chowdhury S, Rudman SM, et al. Serum glucose and risk of cancer: a meta-analysis. BMC Cancer. 2014;14 985. 2407-14-985. 